\title{
RANCANG BANGUN SISTEM DETEKSI KUALITAS KAPUR PERTANIAN BERBASIS \\ FUZZY LOGIC PADA MIKROKONTROLER STM32F4 DI UNIT ZA2 PT. PETROKIMIA \\ GRESIK
}

\author{
1)Muhammad Nizam, 2) Misbah , 3) Denny Irawan \\ 1,2,3)Jurusan Teknik Elektro- Universitas Muhammadiyah Gresik \\ JL. Sumatra No 101, Gresik 61121, Jawa Timur \\ Email : 1)muhnizaamm@gmail.com,2)misbah.grs@gmail.com, 3)den2mas@gmail.com
}

\begin{abstract}
ABSTRAK
Kapur pertanian (KAPTAN) merupakan hasil produk dari unit ZA2 PT. Petrokimia Gresik. KAPTAN sendiri memiliki kandungan kadar air dan kadar ammonia yang menentukan kualitas dari KAPTAN itu sendiri. Kelemahan dari sistem saat ini yaituterlalu lama untuk menganalisa KAPTAN tersebut. Untuk mengantisipasi hal tersebut, dibuatlah alat yang dapat menentukan kualitas KAPTAN berbasis fuzzy logic pada mikrokontroler STM32F4

Teknologi ini menggabungkan dua jenis sensor yaitu sensor kadar amonia (TGS2602) dan sensor kadar air (Soil Moisture Sensor) untuk menentukan kualitas KAPTAN. Pengambilan keputusan pada alat ini menggunakan logika fuzzy sugeno orde nol. Selain itu alat ini juga didesain untuk dapat berkomunikasi secara serial dengan PC dan LCD untuk monitoring kualitas KAPTAN.

Dari hasil pengujian dapat disimpulkan bahwa alat yang telah dibuat dapat mendeteksi kualitas KAPTAN . Dalam pengujian sampel KAPTAN yang berbeda, Alat dapat mendeteksi kualitas KAPTAN dengan baik pada suhu ruangan yang berbeda dan memudahkan pihak produksi dalam mengetahui kualitas KAPTAN dengan cepat.
\end{abstract}

Kata Kunci : KAPTAN, Fuzzy Sugeno, STM32F4.

\section{PENDAHULUAN}

Kapur pertanian (KAPTAN) merupakan hasil produk dari unit ZA2 selain pupuk ZA yang bahan bakunya berasal dari gypsum, amoniak $\left(\mathrm{NH}_{3}\right)$ dan karbon dioksida $\left(\mathrm{CO}_{2}\right)$. KAPTAN dihasilkan pada proses filtrasi. Pada proses filtasi ini terjadi pemisahan strong liquor dan chalk cake. Strong liquor sendiri akan diproses lagi untuk menghasilkan pupuk ZA sedangkan chalk cake sendiri akan dikirim ke pengantongan untuk hasil produk KAPTAN PT PETROKIMIA GRESIK.

KAPTAN sendiri mempunyai banyak manfaat dalam pertanian atau perikanan. Dalam hal pertanian, KAPTAN berfungsi meningkatkan $\mathrm{PH}$ tanah menjadi netral serta memacu pertumbuhan akar. Sedangkan dalam hal perikanan, berfungsi untuk mempertinggi PH tambak yang rendah serta mempercepat proses penguraian bahan organik [5].
KAPTAN berguna untuk bahan baku industry semen yaitu sebagai campuran dalam proses pembuatan semen.

KAPTAN setiap harinya dianalisa oleh unit laboratorium, agar kandungankandungannya dapat diketahui. salah satu kandungan yang di analisa adalah kadar air serta kandungan $\mathrm{NH}_{3}$ pada KAPTAN. dari kandungan tersebut akan sangat mempengaruhi kualitas KAPTAN. Kualitas kapur pertanian yang buruk tidak bisa masuk pada proses pengantongan diakibatkan tidak sesuai dengan standart oleh pihak produksi. Adapun kelemahan dari laboratorium yaitu terlalu lama untuk menganalisa KAPTAN tersebut. Hal ini disebabkan karena banyaknya sampel yang dianalisa laboratorium dalam satu shift, akibatnya pihak produksi terlambat mengetahui kualitas KAPTAN serta resiko seringnya 
kualitas KAPTAN yang tidak bagus masuk kedalam pengantongan dan tidak disimpan terlebih dulu di gudang storage.

Memandang dari pentingnya kualitas KAPTAN yang harus termonitor pihak produksi di unit ZA2 PT PETROKIMIA GRESIK, penulis tertarik untuk memberikan informasi kualitas KAPTAN dengan motode fuzzy logic berdasarkan kandungan kadar air serta $\mathrm{NH}_{3}$ yang bisa dipantau di control room. Maka penulis mengambil judul "Rancang Bangun Sistem Deteksi Kualitas Kapur Pertanian (KAPTAN) berbasis Fuzzy Logic pada Mikrokontroler STM32F4 di Unit ZA2 PT.PETROKIMIA GRESIK”.

\section{TINJAUAN PUSTAKA}

\subsection{Kapur Pertanian (KAPTAN)}

Kapur pertanian (KAPTAN) merupakan hasil produk dari unit ZA2 selain pupuk ZA yang bahan bakunya berasal dari gypsum, amoniak $\left(\mathrm{NH}_{3}\right)$ dan karbon dioksida $\left(\mathrm{CO}_{2}\right)$. KAPTAN dihasilkan pada proses filtrasi. Pada proses filtasi ini terjadi pemisahan strong liquor dan chalk cake. Strong liquor sendiri akan diproses lagi untuk menghasilkan pupuk ZA sedangkan chalk cake sendiri akan dikirim ke pengantongan untuk hasil produk KAPTAN PT PETROKIMIA GRESIK. Chalk cake atau $\mathrm{CaCO}_{3}$ yang dihasilkan pada proses filtrasi tersebut mempunyai komposisi $\mathrm{CaCO}_{3} 85 \%, \mathrm{CaSO}_{4} .2 \mathrm{H}_{2} \mathrm{O}$ maks $4 \%$, $\left(\mathrm{NH}_{4}\right)_{2} \mathrm{SO}_{4}$ maks $2 \%$ yaitu dari kadar amonia dan asam sulfat dari ZA yang tercampur dan $\mathrm{H}_{2} \mathrm{O}$ maks $20 \%$. Standart tersebut diterapkan oleh produksi agar kualitas kapur pertanian tetap terjaga.

\subsection{Mikrokontroler STM32F4 Discovery}

STM32F4 discovery adalah salah satu jenis dari penggunaan prosesor ARM. Fitur yang terdapat pada STM32F4 discovery membantu untuk mempermudah dan mengembangkan aplikasi. Rangkaian Ini mencakup segala sesuatu yang diperlukan untuk pengguna pemula dan pengguna berpengalaman untuk mengaplikasikan dengan cepat dan mudah.

Berdasarkan STM32F407VGT6, terdapat alat ST-LINK/V2 tertanam debug, dua ST MEMS, accelerometer digital dan mikrofon digital, satu DAC audio dengan sopir D speaker kelas terpadu, LED, tombol push button dan konektor micro-AB USB OTG.Board STM32F4 Discovery

\subsection{Sensor Kadar Air dan Kadar Amonia}

Sensor kadar air yang digunakan adalah capasitive soil moisture yaitu dengan mengukur tingkat mositure tanah dengan penginderaan kapasitif. Sensor ini terbuat dari korosi bahan tahan yang memberikan kehidupan pelayanan prima. Modul ini mencakup regulator tegangan on-board yang memberikannya rentang tegangan operasi 3,3 $\sim 5.5 \mathrm{~V}$. ini cocok untuk tegangan rendah MCUs, baik 3.3V dan 5V.

Sedangkan Sensor amonia menggunakan TGS2602 yang mempunyai sinyal analog dan sinyal output pada tingkat yang sama, kisaran sinyal keluaran analog 0$5 \mathrm{~V}$, sinyal analog dapat langsung terhubung dengan akuisisi AD. Sinyal keluaran sinyal tingkat digital yang valid rendah, lampu led, dapat dihubungkan langsung ke port IO mikrokontroler. Sensitivitas sensor bisa disesuaikan, Anda bisa mengatur sensor ambang batas output gas rendah, bisa langsung terhubung ke mikrokontroler.

\subsection{Fuzzy Logic}

Fuzzy berarti samar, kabur atau tidak jelas. Fuzzy istilah yang dipakai oleh Lotfi A Zadeh pada bulan Juli 1964 untuk menyatakan kelompok / himpunan yang dapat dibedakan dengan himpunan lain berdasarkan derajat keanggotaan dengan batasan yang tidak begitu jelas (samar), tidak seperti himpunan klasik yang membedakan keanggotaan himpunan menjadi dua, himpunan anggota atau bukan anggota. Struktur dasar pengendalian Fuzzy. Dalam tahapan-tahapan analisa yang akan dikembangkan untuk membangun Logika Fuzzy ini meliputi: Fuzzifikasi, Basis Pengetahuan Fuzzy, Defuzzifikasi.

\section{METODE PENELITIAN \\ 3.1 Perancangan Sistem}

Perancangan sistem pada rancang bangun sistem deteksi kualitas kapur pertanian berbasis fuzzy logic pada 
mikrokontroler STM32F4 di unit ZA2 PT. Petrokimia Gresik dibagi menjadi 2 bagian yaitu perancangan perangkat keras (hardware) dan perancangan perangkat lunak (software). Perangkat keras terdiri dari modul STM32F4 Discovery, sensor kadar air tanah, sensor amonia, LCD (Liquid Crystal Display), modul USB to TTL dan juga beberapa perangkat penunjang elektronika. Sedangkan Perancangan perangkat lunak dilakukan setelah mengetahui karakteristik kualitas kapur pertanian yang di produksi unit ZA2 PT. Petrokimia Gresik yaitu berdasarkan kandungan kadar air dan gas $\mathrm{NH}_{3}$, setelah itu dilakukan perhitungan untuk menentukan algoritma Logika Fuzzy. Setelah didapatkan algoritma, kemudian dibuat program untuk mikrokontroler dengan software program aplikasi STM32CubeMX dan Keil Uvison5. Aplikasi ini berfungsi sebagai aplikasi programing dari STM32F4 Discovery. Sebagai otak utama dalam alat rancang bangun sistem deteksi kualitas kapur pertanian berbasis fuzzy logic pada mikrokontroler STM32F4 di unit ZA2 PT. Petrokimia Gresik. Perancangan dimulai dari pembuatan flowchart, kemudian penulisan listing code.

\subsection{Basis Algoritma Fuzzy Logic}

Pada basis pengetahuan berisi kriteria pengambilan keputusan dan himpunan fuzzy masing-masing kriteria. Kriteria tersebut digolongkan menjadi :

1. Kadar Air : Kering, Lembab, dan Basah.

2. Kadar $\mathrm{NH}_{3}$ : Zero, Positif Kecil, dan Positif Besar.

Fungsi keanggotaan Kadar Air diambil berdasarkan nilai kadar air kapur pertanian tersebut dari rentang 0-25\% Sedangkan F Fungsi keanggotaan Kadar $\mathrm{NH}_{3}$ diambil berdasarkan nilai kadar $\mathrm{NH}_{3}$ kapur pertanian tersebut dari rentang 0-30PPM. Fungsi keanggotaan kadar air dan $\mathrm{NH}_{3}$ dapat diliat pada tabel 1 dan tabel 2 sedangkan grafik fungsi keanggotaanya seperti pada gambar 1 dan gambar 2 .
Tabel 1. Fungsi Keanggotaan Kadar Air

\begin{tabular}{|c|c|}
\hline Fungsi Keanggotaan & Rentang Nilai \\
\hline Kering & $0-13 \%$ \\
\hline Lembab & $10-20 \%$ \\
\hline Basah & $17-25 \%$ \\
\hline
\end{tabular}

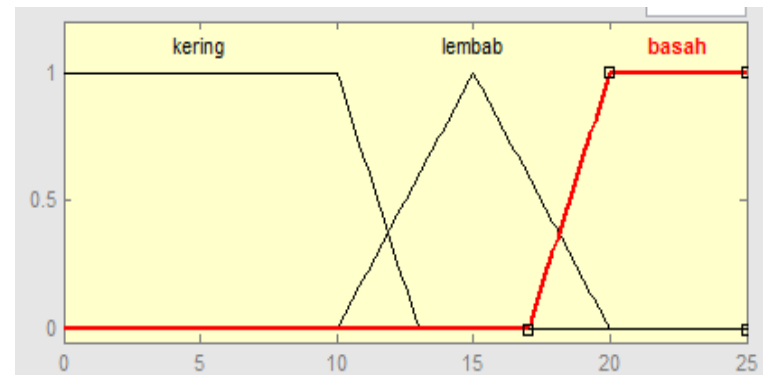

Gambar 1. Grafik Fungsi Keanggotaan Kadar Air

Fungsi Keanggotaan Kadar Air:

$$
\begin{aligned}
\mu[\text { Kering }]=\quad & 1 ; \mathrm{x} \leq 10 \\
& (13-\mathrm{x}) /(13-10) ; 10<\mathrm{x} \leq 13 \\
& 0 ; \mathrm{x} \geq 13 \\
\mu[\text { Lembab }]= & 0 ; \mathrm{x} \leq 10 \text { atau } \mathrm{x} \geq 20 \\
& (\mathrm{x}-10) /(15-10) ; 10<\mathrm{x} \leq 15 \\
& (20-\mathrm{x}) /(20-15) ; 15<\mathrm{x}<20 \\
& 0 ; \mathrm{x} \leq 17 \\
& (\mathrm{x}-17) /(20-17) ; 17<\mathrm{x} \leq 20 \\
& 1 ; \mathrm{x} \geq 20
\end{aligned}
$$

Tabel 2. Fungsi Keanggotaan Kadar $\mathrm{NH}_{3}$

\begin{tabular}{|c|c|}
\hline Fungsi Keanggotaan & Rentang Nilai \\
\hline Zero & 0-10PPM \\
\hline Positif Kecil & 4-15PPM \\
\hline Positif Besar & 10-30PPM \\
\hline
\end{tabular}

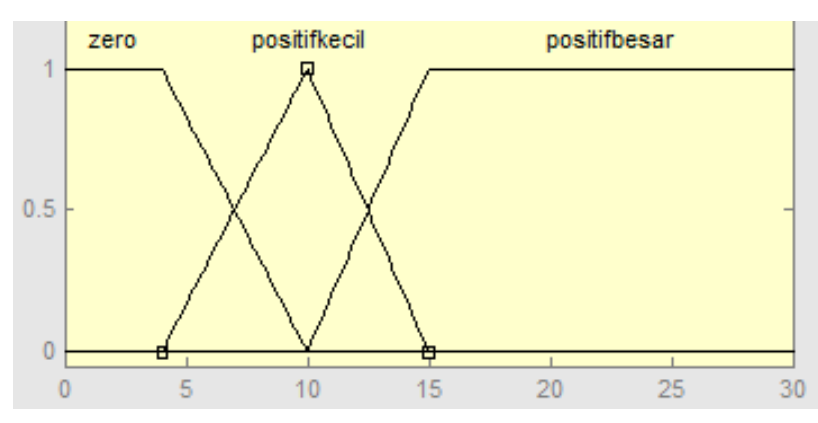

Gambar 2. Grafik Fungsi Keanggotaan Kadar $\mathrm{NH}_{3}$ 
Fungsi Keanggotaan Kadar $\mathrm{NH}_{3}$ :

$$
\begin{aligned}
\mu[\text { Zero }]= & 1 ; \mathrm{x} \leq 4 \\
& (10-\mathrm{x}) /(10-4) ; 4<\mathrm{x} \leq 10 \\
& 0 ; \mathrm{x} \geq 10
\end{aligned}
$$

$\mu[$ Positif Kecil $]=0 ; \mathrm{x} \leq 4$ atau $\mathrm{x} \geq 15$

$$
\begin{aligned}
& (x-4) /(10-4) ; 4<x \leq 10 \\
& (15-x) /(15-10) ; 10<x<15
\end{aligned}
$$

$\mu[$ Positif Besar $]=0 ; x \leq 10$

$$
\begin{aligned}
& (\mathrm{x}-10) /(15-10) ; 10<\mathrm{x} \leq 15 \\
& 1 ; \mathrm{x} \geq 15
\end{aligned}
$$

\subsection{Model Algoritma Fuzzy Logic}

Dalam sistem manajemen model ini akan dibahas mengenai langkah-langkah yang digunakan dalam metode Fuzzy Sugeno [1]. Berikut langkah-langkahnya :

a. Fuzzifikasi : Mengubah masukanmasukan yang nilai kebenarannya bersifat pasti (crisp input) ke dalam bentuk fuzzy input.

b. Inferensi : Melakukan penalaran menggunakan fuzzy Sugeno dilakukan dengan . penggunaan singleton sebagai fungsi keanggotaan dari konsekuen. Singleton adalah sebuah himpunan fuzzy dengan fungsi keanggotaan: pada titik tertentu mempunyai sebuah nilai dan 0 di luar titik tersebut. Output (konsekuen) sistem tidak berupa himpunan fuzzy, melainkan berupa konstanta atau persamaan linear.

c. Defuzzifikasi : Mengubah fuzzy output menjadi crisp value berdasarkan fungsi keanggotaan yang telah ditentukan dengan rumus

$$
z=\frac{\operatorname{apred}_{1} * z_{1}+\operatorname{apred}_{2} * z_{2}+\operatorname{apred}_{3} * z_{3}+\operatorname{apred}_{4} * z_{4}}{\text { apred }_{1}+\operatorname{apred}_{2}+\operatorname{apred}_{3}+\operatorname{apred}_{4}}
$$

\subsection{Arsitektur Alat Dan Cara Kerja}

Dalam proses rancang bangun sistem deteksi kualitas kapur pertanian berbasis fuzzy logic pada mikrokontroler STM32F4 di unit ZA2 PT. Petrokimia Gresik didesain untuk memonitoring kualitas kapur pertanian yang dihasilkan unit ZA2 PT. Petrokimia Gresik dengan metode Fuzzy Logic Sugeno berdasarkan variable kadar air dan $\mathrm{NH}_{3}$.
Melalui data dari pihak produksi bagaimana kualitas kapur pertanian yang baik dari kandungan kadar air dan $\mathrm{NH}_{3}$ yang dideteksi oleh sensor. Dengan program interfasing Delphi maka secara otomatis akan memberikan informasi kepada pihak produksi tentang kualitas kapur pertanian yang dihasilkan. Hal itu telah diatur dalam program STM32F4. Dapat dijelaskan pada gambar 3.

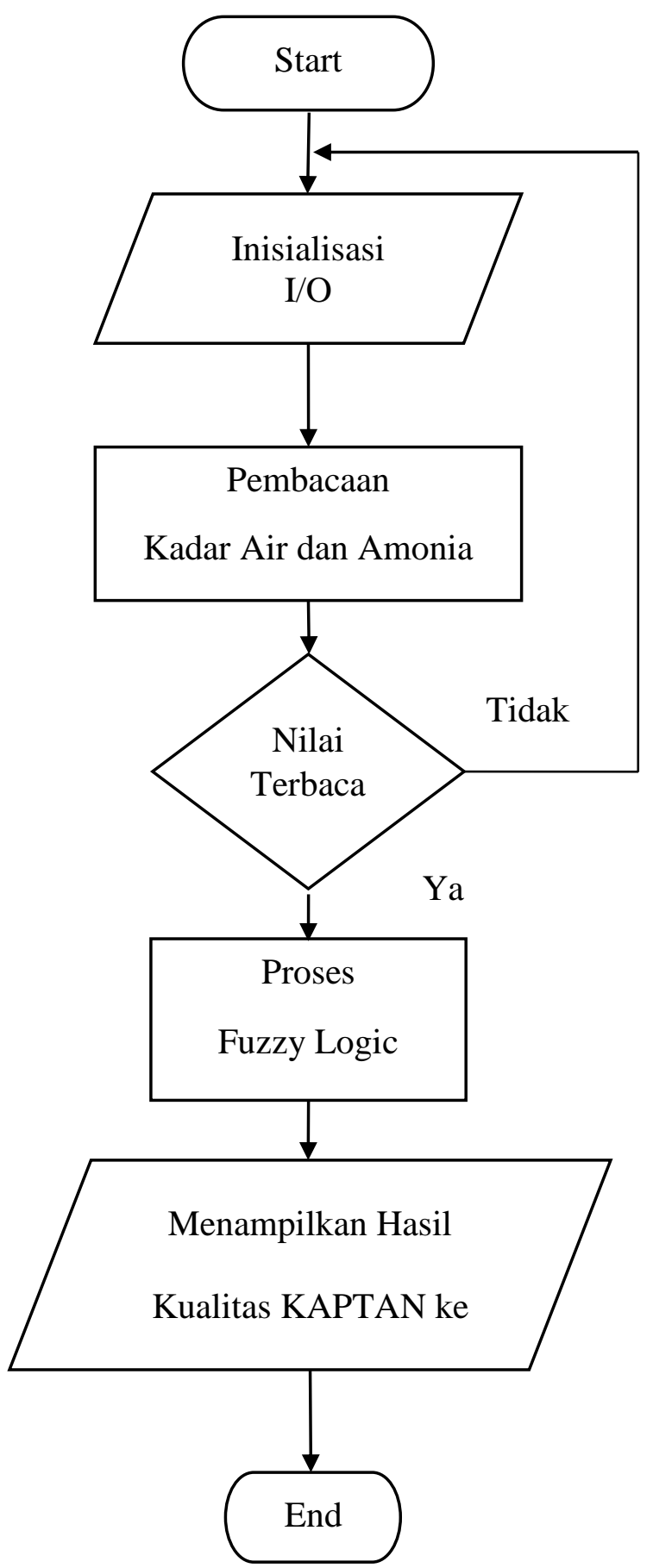

Gambar 3. Flowchart desain sistem deteksi kualitas kapur pertanian berbasis fuzzy logic 


\section{HASIL DAN PEMBAHASAN}

\subsection{Pengujian Sensor Kadar Amonia}

Sebelum mengujikan sensor, sensor gas TGS2602 perlu dilakukan kalibrasi. Pengujian pada sensor gas TGS2602 dilakukan untuk mengetahui sensor tersebut dapat menerima interuksi pada saat diberikan gas ammonia $\left(\mathrm{NH}_{3}\right)$. Sebelum melakukan proses kalibrasi terlebih dahulu disiapkan 10 sampel KAPTAN. Proses kalibrasi sensor TGS2602 dilakukan dengan alat pembanding yaitu alat gas analyzer Multiwarn II sebagai pengukuran kadar amonia dalam satuan PPM. Prosedur kalibrasi yang dilakukan adalah sebagai berikut:

1. Menyiapkan alat dan bahan berupa rangkaian sensor TGS2602.

2. Meletakkan rangkaian sensor TGS2602 pada tabung gas 10 sampel KAPTAN.

3. Meletakkan gas analizer $\mathrm{NH}_{3}$ (Multiwarn) pada tabung gas 10 sample KAPTAN yang sama.

4. Mengamati dan mencatat data yang tertulis yaitu hasil nilai ADC sensor TGS2602 dan hasil nilai PPM pada alat gas analyzer $\mathrm{NH}_{3}$ (Multiwarn) dalam bentuk tabel.

5. Mengolah data dalam grafik dan menggunakan model regresi antara kedua variabel tersebut, dan diketahui koefisien determinasi yang membuktikan variabel PPM ammonia dipengaruhi oleh variabel nilai ADC dan kemudian menuliskan rumus pada program.

Pada Gambar 4 menunjukkan grafik hubungan antara nilai pembacaan PPM analyzer gas amonia Multiwarn dan nilaiADC keluaran sensor sebanyak 10 kali percobaan. Grafik tersebut sesuai dengan karateristik sensor gas TGS2602, terlihat pada gambar tersebut nilai $\mathrm{y}=0.0683 \mathrm{x}+0.8641$ merupakan model regresi linier antara kedua variabel tersebut, sedangkan nilai $\mathrm{R}^{2}=$ 0.9551 disebut sebagai koefisien determinasi yang berarti variabel PPM amonia dipengaruhi oleh variabel nilai ADC sebesar $95,51 \%$.

\section{Grafik Hubungan Vout dengan PPM}

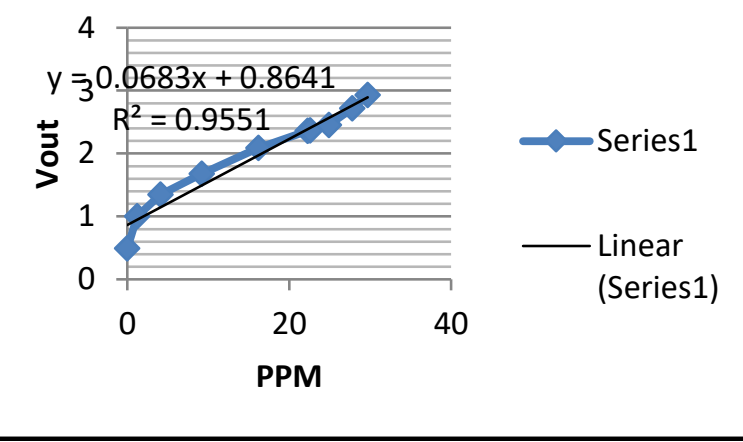

Gambar 4 Grafik Hubungan Vout Dengan PPM Amonia

Berikut ini data yang diperoleh dari pengujian sensor TGS2602 menggunakan regresi linear pada Gambar 4 beserta nilai error yang dihasilkan dengan pada alat tugas akhir.

Tabel 3 Pengujian Sensor Kadar Amonia Pada Sampel KAPTAN

\begin{tabular}{|c|c|c|c|c|}
\hline $\begin{array}{c}\text { Sam } \\
\text { pel } \\
\text { KA } \\
\text { PT } \\
\text { AN }\end{array}$ & $\begin{array}{c}\text { PPM } \\
\text { warm } \\
\text { II }\end{array}$ & Vout & $\begin{array}{c}\text { Plat } \\
\text { Aasil } \\
\text { Tugas } \\
\text { Akhir }\end{array}$ & Deviasi \\
\hline 1 & 0 & 0.49 & 0.4375 & 0.4375 \\
\hline 2 & 1.2 & 1 & 1.6402 & 0.4402 \\
\hline 3 & 4.1 & 1.35 & 6.4562 & 2.3562 \\
\hline 4 & 9.2 & 1.68 & 10.9698 & 1.7698 \\
\hline 5 & 16.2 & 2.09 & 16.6706 & 0.4706 \\
\hline 6 & 22.3 & 2.36 & 20.4226 & -1.8774 \\
\hline 7 & 22.6 & 2.37 & 20.557 & -2.043 \\
\hline 8 & 24.9 & 2.45 & 21.677 & -3.223 \\
\hline 9 & 27.8 & 2.72 & 25.5634 & -2.2366 \\
\hline 10 & 29.7 & 2.93 & 28.4866 & -1.2134 \\
\hline
\end{tabular}


Keterangan :

X1 = Nilai rata-rata PPM Multiwarn II

$\mathrm{X} 2$ = Nilai rata-rata PPM Alat Tugas

Akhir

$$
\begin{aligned}
& \mathrm{D}=\text { Nilai rata-rata Deviasi } \\
& \begin{aligned}
\text { Error } & =|(\mathrm{X} 2-\mathrm{X} 1) / \mathrm{X} 1| \times 100 \% \\
& =|-0.51191 / 15.8| \times 100 \% \\
& =3.23 \%
\end{aligned}
\end{aligned}
$$

\subsection{Pengujian Sensor Kadar Air}

Kalibrasi dibutukan sebelum melakukan pengujian terhadap sensor kadar air, sama seperti kalibrasi sensor kadar amonia, tetapi dengan membandingkan nilai ADC sensor capacitive soil moisture dengan hasil laboratorium unit ZA2. Media yang diukur langsung menggunakan kapur pertanian dalam proses kalibrasi.

Prosedur kalibrasi yang dilakukan adalah sebagai berikut:

1. Menyiapkan alat dan bahan berupa rangkaian sensor capacitive soil moisture.

2. Meletakkan rangkaian sensor capacitive soil moisture pada tabung gas 10 sampel KAPTAN.

3. mencatat data yang tertulis yaitu hasil nilai ADC pada sensor capacitive soil moisture.

4. menyerahkan 10 sampel kaptan pada laboratorium unit ZA2.

5. mencatat data yang tertulis yaitu hasil nilai ADC pada sensor capacitive soil moisture dan hasil nilai $\% \mathrm{H}_{2} \mathrm{O}$ pada hasil labaratorium dalam bentuk tabel.

6. Mengolah data dalam grafik dan menggunakan model regresi power antara kedua variable tersebut, dan diketahui koefisien determinasi yang membuktikan variabel $\% \mathrm{H}_{2} \mathrm{O}$ dipengaruhi oleh variabel nilai ADC dan kemudian menuliskan rumus pada program.

Pada Gambar 5 menunjukkan grafik hubungan antara nilai pembacaan $\% \mathrm{H}_{2} \mathrm{O}$ pada hasil laboratorium dan nilai ADC keluaran sensor sebanyak 10 kali percobaan. Grafik tersebut sesuai dengan karateristik sensor capacitive soil moisture terlihat pada gambar tersebut nilai $\mathrm{y}=$ $0.0371 \mathrm{x}+2.1642$ merupakan model regresi linier antara kedua variabel tersebut, sedangkan nilai $\mathrm{R}^{2}=0.962$ disebut sebagai koefisien determinasi yang berarti variabel $\% \mathrm{H}_{2} \mathrm{O}$ dipengaruhi oleh variabel nilai ADC sebesar 96,2\%.

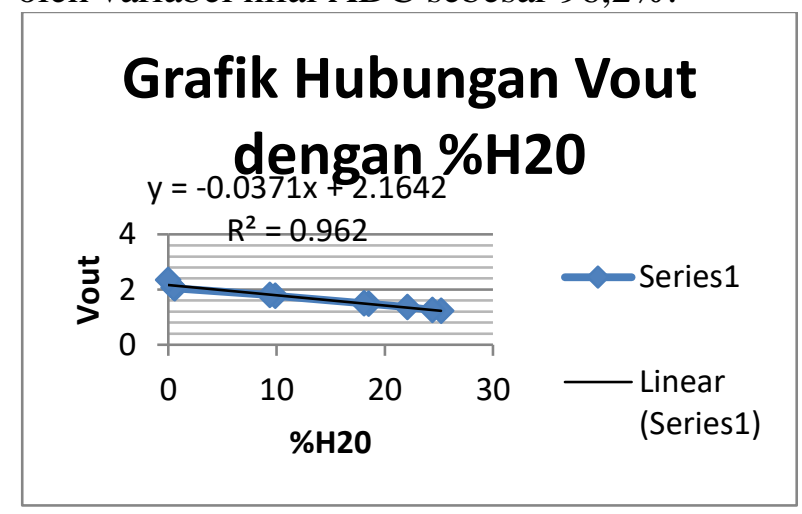

Gambar 5. Grafik Hubungan Vout Dengan $\% \mathrm{H}_{2} \mathrm{O}$

Berikut ini data yang diperoleh dari pengujian soil moisture sensor menggunakan regresi linear pada Gambar 5 beserta nilai error yang dihasilkan dengan pada alat tugas akhir.

Tabel 4 Pengujian Sensor Kadar Air Pada Sampel KAPTAN

\begin{tabular}{|c|c|c|c|c|}
\hline & & & $\begin{array}{c}\% \mathrm{H}_{2} 0 \\
\text { Hasil Alat } \\
\text { Tugas } \\
\text { Akhir }\end{array}$ & \\
$\begin{array}{c}\text { Sam } \\
\text { pel } \\
\text { KA } \\
\text { PT } \\
\text { AN }\end{array}$ & $\begin{array}{c}\text { \%abor } \\
\text { atoriu } \\
\text { m }\end{array}$ & $\begin{array}{c}\text { Vou } \\
\mathrm{t}\end{array}$ & & Deviasi \\
\hline 1 & 25.2 & 1.23 & 23.673 & -1.527 \\
\hline 2 & 24.4 & 1.26 & 23.0042 & -1.3958 \\
\hline 3 & 22.1 & 1.36 & 20.5798 & -1.5202 \\
\hline 4 & 18.5 & 1.48 & 17.194 & -1.306 \\
\hline 5 & 18.1 & 1.5 & 16.6924 & -1.4076 \\
\hline 6 & 9.9 & 1.77 & 9.7536 & -0.1464 \\
\hline 7 & 9.4 & 1.8 & 9.1057 & -0.2943 \\
\hline 8 & 0.6 & 2.05 & 2.4386 & 1.8386 \\
\hline 9 & 0.5 & 2.07 & 2.0415 & 1.5415 \\
\hline 10 & 0 & 2.35 & 1.0742 & 1.0742 \\
\hline
\end{tabular}


Keterangan :

$\mathrm{X} 1=$ Nilai rata-rata $\% \mathrm{H} 20$ Laboratorium

$\mathrm{X} 2=$ Nilai rata-rata $\% \mathrm{H} 20$ Alat Tugas

Akhir

$$
\begin{aligned}
& \mathrm{D}=\text { Nilai rata-rata Deviasi } \\
& \begin{aligned}
\text { Error } & =|(\mathrm{X} 2-\mathrm{X} 1) / \mathrm{X} 1| \times 100 \% \\
& =|-0.3143 / 12.87| \times 100 \% \\
& =2.44 \%
\end{aligned}
\end{aligned}
$$

\subsection{Pengujian Fuzzy Logic}

Pada pengujian alat selanjutnya adalah pengujian Fuzzy Logic. Dari hasil pembacaan nilai ADC kedua sensor tersebut akan diproses menggunakan logika fuzzy untuk menghasilkan nilai tengah yang pada program dilambangkan " $z t$ ". Nilai tengah ini nantinya dimasukkan pada beberapa range dan range tersebut tergolongkan pada kondisi kualitas kapur pertanian (KAPTAN). Metode fuzzy yang digunakan pada alat ini yaitu menggunakan metode fuzzy Sugeno orde satu.

\subsubsection{Fuzzification}

Tahapan awal proses Fuzzifikasi adalah menentukan parameter-parameter fungsi keanggotaan pada setiap himpunan Fuzzy masukan. Pada pemrograman Fuzzifikasi ini digunakan parameter fungsi keanggotaan masukan berupa variabel kadar air dan variabel kadar amonia pada KAPTAN. Fungsi keanggotaan ini diperoleh dari pengujian langsung pada KAPTAN oleh pihak produksi, pada saat KAPTAN sangat sesuai sampai tidak sesuai kemudian data yang diperoleh dibuat kedalam fungsi keanggotaan fuzzy.

\subsubsection{Rule Fuzzy}

Tabel 5 Rule Fuzzy

\begin{tabular}{|l|l|l|l|}
\hline $\begin{array}{l}\text { Sensor } \\
\text { II/I }\end{array}$ & Kering & Lembab & Basah \\
\hline Zero & $\begin{array}{l}\text { Sangat } \\
\text { Sesuai }\end{array}$ & $\begin{array}{l}\text { Sangat } \\
\text { Sesuai }\end{array}$ & $\begin{array}{l}\text { Tidak } \\
\text { Sesuai }\end{array}$ \\
\hline $\begin{array}{l}\text { Positif } \\
\text { kecil } \\
\text { (PK) }\end{array}$ & Sesuai & Sesuai & $\begin{array}{l}\text { Tidak } \\
\text { Sesuai }\end{array}$ \\
\hline $\begin{array}{l}\text { Positif } \\
\text { Besar } \\
\text { (PB) }\end{array}$ & Sesuai & $\begin{array}{l}\text { Tidak } \\
\text { Sesuai }\end{array}$ & $\begin{array}{l}\text { Tidak } \\
\text { Sesuai }\end{array}$ \\
\hline
\end{tabular}

Keterangan Sensor I = Kadar Air dan Sensor $\mathrm{II}=$ Kadar Amonia.

\subsubsection{Defuzzifikasi}

Defuzzifikasi, yaitu mengubah himpunan Fuzzy keluaran menjadi keluaran tegas (crisp). Pengubahan ini diperlukan karena konstanta keputusan daginghanya mengenal nilai tegas sebagai variabel parameter.Perancangan ini, menggunakan sebuah himpunan Fuzzy keluaran dengan fungsi keanggotaannya berupa singleton.

Nilai tegas (crisp) keluaran diperoleh dari himpunan-himpunan Fuzzy keluaran dengan menggunakan metode rata-rata terbobot.Pada perancangan digunakan nilai 10 sampai 90 agar keluaran crips (zt) mempunyai range mendekati 0 sampai 100 dengan nilai 30 yaitu Tidak sesuai, 60 yaitu Sesuai, dan 90 yaitu Sangat Sesuai . Fungsi anggota keluaran dapat dilihat pada Gambar 6

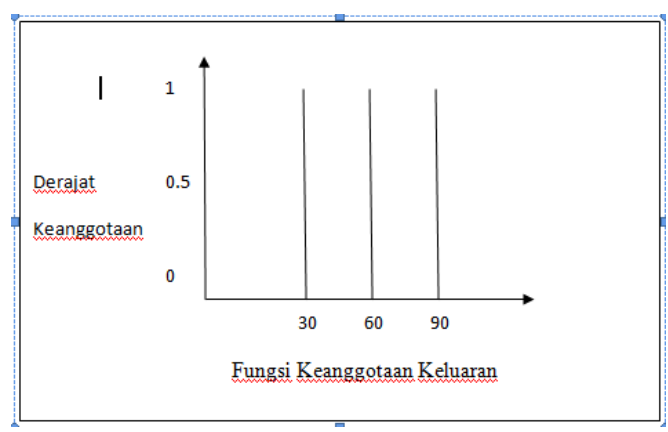

\section{Gambar 6 Fungsi keanggotaan keluaran}

pada program.

\subsubsection{Fuzzy decision index}

Dari nilai defuzzifikasi yang ada kemudian dibuat range keputusan kedalam nilai linguistik dengan logika dalam satuan persen nilai kualitas KAPTAN sangat sesuai, sesuai atau tidak sesuai sebagai berikut :

a) if $(\mathrm{zt}>75)$ then kualitas $=(60-\mathrm{zt}) /(60-$ $90) * 100 \%$ sangatsesuai

b) else if $(\mathrm{zt}>=60 \quad \& \& \quad \mathrm{zt}<75)$ then kualitas $=((90-\mathrm{zt}) /(90-60)) * 100 \%$ sesuai

c) else if $(z t>=45 \quad \& \& \quad z t<60)$ then kualitas $=((30-\mathrm{zt}) /(30-60)) * 100 \%$ sesuai

d) else if $(\mathrm{zt}>=30 \quad \& \& \quad \mathrm{zt}<45)$ then kualitas $=((60-\mathrm{zt}) /(60-30)) * 100 \%$ tidaksesuai 


\subsection{Pengujian Alat dalam informasi kualitas kapur pertanian}

Pada proses ini dilakukan pencatatan data hasil kualitas KAPTAN dengan algoritma fuzzy logic sugeno. Dari mengelompokkan nilai kadar air dan $\mathrm{NH}_{3}$, maka akan didapat output dari kategori persen kualitas KAPTAN yaitu \%TS (Tidak Sesuai), \%S (Sesuai), dan \%SS (Sangat Sesuai). Dari 5 sampel yang diujikan akan diketahui kategori kualitas masing-masing sampel melalui LCD dan Delphi. Proses pengambilan sampel data ini dilakukan pada 3 tempat berbeda berdasarkan suhu ruangan pengambilan sampel untuk dibandingkan. Hasil dari tampilan LCD dan Delphi juga akan dibandingkan apakah sama atau tidak.

Tabel 6 Nilai Informasi Kualitas KAPTAN pada LCD dan Delphi Pada Suhu Ruangan $30^{\circ}$ Celcius

\begin{tabular}{|c|c|c|c|c|c|c|c|}
\hline $\begin{array}{c}\text { Sam } \\
\text { pel } \\
\text { KAP } \\
\text { TA } \\
\text { N }\end{array}$ & $\begin{array}{c}\mathrm{Ka} \\
\mathrm{dar} \\
\mathrm{Ai} \\
\mathrm{r}\end{array}$ & $\begin{array}{c}\mathrm{Kad} \\
\text { ar } \\
\mathrm{NH}_{3}\end{array}$ & $\begin{array}{l}Z \\
t\end{array}$ & $\begin{array}{c}\text { Nil } \\
\text { ai } \\
\text { Kua } \\
\text { litas } \\
\text { Pad } \\
\text { a } \\
\text { LC } \\
\text { D }\end{array}$ & $\begin{array}{c}\text { Nil } \\
\text { ai } \\
\text { Kua } \\
\text { litas } \\
\text { Pad } \\
\text { a } \\
\text { Del } \\
\text { phi }\end{array}$ & $\begin{array}{c}\text { Nil } \\
\text { ai } \\
\text { LC } \\
\text { D } \\
\text { da } \\
\text { n } \\
\text { De } \\
\text { lph } \\
\text { i }\end{array}$ & $\begin{array}{c}\text { Nila } \\
\text { i } \\
\text { Dari } \\
\text { Pro } \\
\text { duk } \\
\text { si } \\
\text { ZA } \\
2\end{array}$ \\
\hline 1 & $\begin{array}{c}22 . \\
1 \\
\%\end{array}$ & $\begin{array}{c}29.8 \\
\text { PP } \\
\text { M }\end{array}$ & $\begin{array}{l}3 \\
0\end{array}$ & $\begin{array}{c}100 \\
\% \\
\text { TS }\end{array}$ & $\begin{array}{c}100 \\
\% \\
\mathrm{TS}\end{array}$ & $\begin{array}{l}\mathrm{Sa} \\
\mathrm{ma}\end{array}$ & $\begin{array}{c}\text { Bur } \\
\text { uk }\end{array}$ \\
\hline 2 & $\begin{array}{c}13 . \\
5 \\
\%\end{array}$ & $\begin{array}{c}15.7 \\
\mathrm{PP} \\
\mathrm{M}\end{array}$ & $\begin{array}{l}3 \\
0\end{array}$ & $\begin{array}{c}100 \\
\% \\
\text { TS }\end{array}$ & $\begin{array}{c}100 \\
\% \\
\text { TS }\end{array}$ & $\begin{array}{l}\mathrm{Sa} \\
\mathrm{ma}\end{array}$ & $\begin{array}{c}\text { Bur } \\
\text { uk }\end{array}$ \\
\hline 3 & $\begin{array}{c}7.6 \\
\%\end{array}$ & $\begin{array}{c}22.1 \\
\mathrm{PP} \\
\mathrm{M}\end{array}$ & $\begin{array}{l}6 \\
0\end{array}$ & $\begin{array}{l}100 \\
\% \mathrm{~S}\end{array}$ & $\begin{array}{l}100 \\
\% \mathrm{~S}\end{array}$ & $\begin{array}{l}\mathrm{Sa} \\
\mathrm{ma}\end{array}$ & $\begin{array}{c}\text { Bai } \\
\text { k }\end{array}$ \\
\hline 4 & $\begin{array}{c}2.2 \\
\%\end{array}$ & $\begin{array}{c}10.8 \\
\mathrm{PP} \\
\mathrm{M}\end{array}$ & $\begin{array}{l}6 \\
0\end{array}$ & $\begin{array}{l}100 \\
\% \mathrm{~S}\end{array}$ & $\begin{array}{l}100 \\
\% \mathrm{~S}\end{array}$ & $\begin{array}{l}\mathrm{Sa} \\
\mathrm{ma}\end{array}$ & $\begin{array}{c}\text { Bai } \\
\text { k }\end{array}$ \\
\hline 5 & $\begin{array}{c}2.3 \\
\%\end{array}$ & $\begin{array}{l}7.4 \mathrm{P} \\
\mathrm{PM}\end{array}$ & $\begin{array}{l}7 \\
3\end{array}$ & $\begin{array}{c}56 . \\
7 \% \\
\text { S }\end{array}$ & $\begin{array}{c}56 . \\
7 \% \\
\mathrm{~S}\end{array}$ & $\begin{array}{l}\mathrm{Sa} \\
\mathrm{ma}\end{array}$ & $\begin{array}{c}\text { Bai } \\
\text { k }\end{array}$ \\
\hline
\end{tabular}

Tabel 7 Nilai Informasi Kualitas KAPTAN pada LCD dan Delphi Pada Suhu Ruangan $25^{\circ}$ Celcius

\begin{tabular}{|c|c|c|c|c|c|c|c|}
\hline Sam & $\mathrm{Ka}$ & $\mathrm{Kad}$ & $\mathrm{Z}$ & $\mathrm{Nil}$ & $\mathrm{Nil}$ & $\mathrm{Nil}$ & Nila \\
pel & $\mathrm{da}$ & $\mathrm{ar}$ & $\mathrm{t}$ & ai & ai & ai & i \\
$\mathrm{KA}$ & $\mathrm{r}$ & $\mathrm{NH}_{3}$ & & $\mathrm{Ku}$ & $\mathrm{Ku}$ & $\mathrm{LC}$ & $\mathrm{Dar}$ \\
\hline
\end{tabular}

\begin{tabular}{|c|c|c|c|c|c|c|c|}
\hline $\begin{array}{c}\text { PTA } \\
\mathrm{N}\end{array}$ & $\begin{array}{c}\mathrm{Ai} \\
\mathrm{r}\end{array}$ & & & $\begin{array}{c}\text { alit } \\
\text { as } \\
\text { Pad } \\
\text { a } \\
\text { LC } \\
\text { D }\end{array}$ & $\begin{array}{c}\text { alit } \\
\text { as } \\
\text { Pad } \\
\text { a } \\
\text { Del } \\
\text { phi }\end{array}$ & $\begin{array}{c}\text { D } \\
\mathrm{da} \\
\mathrm{n} \\
\mathrm{De} \\
\mathrm{lph} \\
\mathrm{i}\end{array}$ & $\begin{array}{c}\mathrm{i} \\
\text { Pro } \\
\text { duk } \\
\text { si } \\
\text { ZA } \\
2\end{array}$ \\
\hline 1 & $\begin{array}{c}22 . \\
3 \\
\%\end{array}$ & $\begin{array}{c}28.2 \\
\text { PP } \\
\text { M }\end{array}$ & $\begin{array}{l}3 \\
0\end{array}$ & $\begin{array}{c}100 \\
\% \\
\mathrm{TS}\end{array}$ & $\begin{array}{c}100 \\
\% \\
\text { TS }\end{array}$ & $\begin{array}{l}\mathrm{Sa} \\
\mathrm{ma}\end{array}$ & $\begin{array}{l}\text { Bur } \\
\text { uk }\end{array}$ \\
\hline 2 & $\begin{array}{c}13 . \\
7 \\
\%\end{array}$ & $\begin{array}{c}15.5 \\
\text { PP } \\
\text { M }\end{array}$ & $\begin{array}{l}3 \\
0\end{array}$ & $\begin{array}{c}100 \\
\% \\
\mathrm{TS}\end{array}$ & $\begin{array}{c}100 \\
\% \\
\text { TS }\end{array}$ & $\begin{array}{l}\mathrm{Sa} \\
\mathrm{ma}\end{array}$ & $\begin{array}{c}\text { Bur } \\
\text { uk }\end{array}$ \\
\hline 3 & $\begin{array}{c}7.7 \\
\%\end{array}$ & $\begin{array}{c}21.5 \\
\text { PP } \\
\text { M }\end{array}$ & $\begin{array}{l}6 \\
0\end{array}$ & $\begin{array}{c}100 \\
\% \\
\mathrm{~S}\end{array}$ & $\begin{array}{c}100 \\
\% \\
\mathrm{~S} \\
\end{array}$ & $\begin{array}{l}\mathrm{Sa} \\
\mathrm{ma}\end{array}$ & $\begin{array}{c}\text { Bai } \\
\mathrm{k}\end{array}$ \\
\hline 4 & $\begin{array}{c}2.4 \\
\%\end{array}$ & $\begin{array}{c}10.6 \\
\mathrm{PP} \\
\mathrm{M}\end{array}$ & $\begin{array}{l}6 \\
0\end{array}$ & $\begin{array}{c}100 \\
\% \\
\mathrm{~S} \\
\end{array}$ & $\begin{array}{c}100 \\
\% \\
\mathrm{~S} \\
\end{array}$ & $\begin{array}{l}\mathrm{Sa} \\
\mathrm{ma}\end{array}$ & $\begin{array}{c}\text { Bai } \\
\mathrm{k}\end{array}$ \\
\hline 5 & $\begin{array}{c}2.4 \\
\%\end{array}$ & $\begin{array}{l}6.9 \mathrm{P} \\
\mathrm{PM}\end{array}$ & $\begin{array}{c}7 \\
5 . \\
5\end{array}$ & $\begin{array}{l}51 . \\
7 \% \\
\text { SS }\end{array}$ & $\begin{array}{l}51 . \\
7 \% \\
\text { SS }\end{array}$ & $\begin{array}{l}\mathrm{Sa} \\
\mathrm{ma}\end{array}$ & $\begin{array}{c}\text { Bai } \\
\text { k }\end{array}$ \\
\hline
\end{tabular}

Tabel 8 Nilai Informasi Kualitas KAPTAN pada LCD dan Delphi Pada Suhu Ruangan $16^{\circ}$ Celcius

\begin{tabular}{|c|c|c|c|c|c|c|c|}
\hline $\begin{array}{c}\text { Sam } \\
\text { pel } \\
\text { KA } \\
\text { PTA } \\
\text { N }\end{array}$ & $\begin{array}{c}\mathrm{Ka} \\
\mathrm{da} \\
\mathrm{r} \\
\mathrm{Ai} \\
\mathrm{r}\end{array}$ & $\begin{array}{c}\mathrm{Kad} \\
\text { ar } \\
\mathrm{NH}_{3}\end{array}$ & $\begin{array}{l}Z \\
t\end{array}$ & $\begin{array}{c}\text { Nil } \\
\text { ai } \\
\mathrm{Ku} \\
\text { alit } \\
\text { as } \\
\text { Pad } \\
\text { a } \\
\text { LC } \\
\text { D }\end{array}$ & $\begin{array}{c}\text { Nila } \\
\text { i } \\
\text { Kua } \\
\text { litas } \\
\text { Pad } \\
\text { a } \\
\text { Del } \\
\text { phi }\end{array}$ & $\begin{array}{c}\text { Nil } \\
\text { ai } \\
\text { LC } \\
\text { D } \\
\text { da } \\
\text { n } \\
\text { De } \\
\text { lph } \\
\text { i }\end{array}$ & $\begin{array}{c}\text { Nil } \\
\text { ai } \\
\text { Dar } \\
\text { i } \\
\text { Pro } \\
\text { duk } \\
\text { si } \\
\text { ZA } \\
2 \\
\end{array}$ \\
\hline 1 & $\begin{array}{c}22 \\
.6 \\
\% \\
\end{array}$ & $\begin{array}{c}27.1 \\
\mathrm{PP} \\
\mathrm{M}\end{array}$ & $\begin{array}{l}3 \\
0\end{array}$ & $\begin{array}{c}100 \\
\% \\
\mathrm{TS}\end{array}$ & $\begin{array}{c}100 \\
\% \\
\text { TS }\end{array}$ & $\begin{array}{l}\mathrm{Sa} \\
\mathrm{ma}\end{array}$ & $\begin{array}{c}\text { Bur } \\
\text { uk }\end{array}$ \\
\hline 2 & $\begin{array}{c}13 \\
.9 \\
\% \\
\end{array}$ & $\begin{array}{c}14.5 \\
\text { PP } \\
\text { M }\end{array}$ & $\begin{array}{l}3 \\
3 . \\
4\end{array}$ & $\begin{array}{l}88 . \\
6 \% \\
\text { TS }\end{array}$ & $\begin{array}{l}88.6 \\
\% \mathrm{~T} \\
\mathrm{~S} \\
\end{array}$ & $\begin{array}{l}\mathrm{Sa} \\
\mathrm{ma}\end{array}$ & $\begin{array}{c}\text { Bur } \\
\text { uk }\end{array}$ \\
\hline 3 & $\begin{array}{l}8 . \\
0 \\
\%\end{array}$ & $\begin{array}{c}20.4 \\
\mathrm{PP} \\
\mathrm{M}\end{array}$ & $\begin{array}{l}6 \\
0\end{array}$ & $\begin{array}{c}100 \\
\% \\
\mathrm{~S} \\
\end{array}$ & $\begin{array}{l}100 \\
\% \mathrm{~S}\end{array}$ & $\begin{array}{l}\mathrm{Sa} \\
\mathrm{ma}\end{array}$ & $\begin{array}{c}\text { Bai } \\
\mathrm{k}\end{array}$ \\
\hline 4 & $\begin{array}{c}2 . \\
8 \\
\%\end{array}$ & $\begin{array}{l}9.3 \mathrm{P} \\
\mathrm{PM}\end{array}$ & $\begin{array}{l}6 \\
3 . \\
5\end{array}$ & $\begin{array}{c}88 . \\
3 \% \\
\mathrm{~S}\end{array}$ & $\begin{array}{c}88.3 \\
\% \mathrm{~S}\end{array}$ & $\begin{array}{l}\mathrm{Sa} \\
\mathrm{ma}\end{array}$ & $\begin{array}{c}\text { Bai } \\
k\end{array}$ \\
\hline 5 & $\begin{array}{c}2 . \\
8 \\
\% \\
\end{array}$ & $\begin{array}{l}5.8 \mathrm{P} \\
\mathrm{PM}\end{array}$ & $\begin{array}{l}8 \\
1\end{array}$ & $\begin{array}{c}70 \\
\% \\
\mathrm{SS} \\
\end{array}$ & $\begin{array}{c}70 \\
\% \\
\text { SS } \\
\end{array}$ & $\begin{array}{l}\mathrm{Sa} \\
\mathrm{ma}\end{array}$ & $\begin{array}{c}\text { Bai } \\
\text { k }\end{array}$ \\
\hline
\end{tabular}


Dari pengujian 5 sampel KAPTAN pada ruangan dengan suhu berbeda yaitu pada suhu $30^{\circ} \mathrm{C}, 25^{\circ} \mathrm{C}$, dan $16^{\circ} \mathrm{C}$ yang terdapat pada Tabel 6, Tabel 7, dan Tabel 8 dapat dianalisa tidak terjadi perubahan yang signifikan dari nilai sensor kadar air dan ammonia. Dari nilai kadar air, perubahan nilai yg dilakukan di 3 ruangan dengan suhu berbeda mempunyai perubahan nilai sekitar $0.1-0.5 \% \quad \mathrm{H}_{2} 0$. Sedangkan pada nilai kadar ammonia, perubahan nilai yg dilakukan di 3 ruangan dengan suhu berbeda mempunyai perubahan nilai sekitar 1-3PPM ammonia. Penyampaian informasi pada LCD dan Delphi untuk pengujian selalu bernilai sama dan perbandingan dengan keputusan dari produksi ZA2 menunjukan $100 \%$ kesamaan hasil.

\section{PENUTUP}

\subsection{Kesimpulan}

Berdasarkan penelitian ini, logika fuzzy dengan metode sugeno orde 0 ini dapat diterapkan sebagai sistem pendukung untuk mengetahui kualitas kapur pertanian (KAPTAN), yang ditunjukkan berdasarkan hasil pengolahan dan pengujian akurasi terhadap data-data yang diteliti. Berdasarkan pengujian dan analisis yang dilakukan didapatkan kesimpulan sebagai berikut :

1. Saat dilakukan pengujian pembacaan sensor kadar ammonia mempunyai grafik tersebut sesuai dengan karateristik sensor gas TGS2602, terlihat pada gambar tersebut nilai $\mathrm{y}=$ $0.0683 x+0.8641$ merupakan model regresi linier antara kedua variabel tersebut dan pengujian sensor ammonia pada alat tugas akhir memliki error $3.23 \%$

2. Saat dilakukan pengujian pembacaan sensor kadar air mempunyai Grafik tersebut sesuai dengan karateristik sensor capacitive soil moisture terlihat pada gambar tersebut nilai $\mathrm{y}=$ $0.0371 \mathrm{x}+2.1642$ merupakan model regresi linier antara kedua variabel tersebut dan pengujian sensor ammonia pada alat tugas akhir memliki error $2.44 \%$.
3. Dari nilai defuzzifikasi yang ada kemudian dibuat range keputusan kedalam nilai linguistik dengan logika dalam satuan persen nilai kualitas KAPTAN sangat sesuai, sesuai atau tidak sesuai dengan diberikan dalam satuan persen.

4. Dari nilai kadar air, perubahan nilai yg dilakukan di 3 ruangan dengan suhu berbeda yaitu pada suhu $30^{\circ} \mathrm{C}, 25^{\circ} \mathrm{C}$, $16^{\circ} \mathrm{C}$, mempunyai perubahan nilai sekitar $0.1-0.5 \% \mathrm{H}_{2} 0$. Sedangkan pada nilai kadar ammonia, perubahan nilai yg dilakukan di 3 ruangan dengan suhu berbeda mempunyai perubahan nilai sekitar 1-3PPM ammonia. Penyampaian informasi pada LCD dan Delphi untuk pengujian selalu bernilai sama. Dengan kata lain, penyampaian informasi kualitas KAPTAN telah benar.

5. Nilai dari alat memiliki $100 \%$ kesamaan hasil dari keputusan produksi ZA2 dalam kualitas KAPTAN.

\subsection{Saran}

1. Dapat dilakukan perancangan atau penambahan sistem yang lebih baik dengan perubahan fungsi keanggotaan dari parameter kadar air dan amonia yang keluar pada daging serta fungsi keluaran agar memperoleh respon yang lebih baik.

2. Menambahkan parameter lain agar hasil yang diperoleh semakin akurat dengan kordinasi dengan pihak produksi ZA2

3. Mencoba menggunakan algoritma pengambilan keputusan yang lain untuk merancang pengambilan keputusan seperti jaringan saraf tiruan.

4. Penyempurnaan cover/ kemasan untuk menjaga life time alat.

5. Mencoba antarmuka dengan PC melalui kabel serial RS485 sehingga memungkinkan penyampaian informasi yang lebih jauh dalam jarak. 


\section{DAFTAR PUSTAKA}

[1.] Wahyujati, S. T. (2011). Implementasi metode fuzzy logic untuk pengaturan kelembaban tanah pada tanaman cabai. Surabaya: Institut Teknologi Sepuluh November.

[2.] Yudho, Ahmad. 2013. Instrumen Ukur Kadar Kebutuhan Pupuk Urea Pada Tanaman Jagung Menggunakan Fuzzy Logic. Jurnal Teknik Elektro Universitas Jember: Jember.

[3.] Sri Kusuma Dewi dan Hari Purnomo. 2010. Aplikasi Logika Fuzzy untuk Pendukung Keputusan. Yogyakarta: Graha Ilmu.

[4.] www.st.com. [diakses 03 Februari 2018]

[5.] www.petrokimiagresik.com/Pupuk/Kapur-Pertanian. [diakses 03 Februari 2018]

[6.] www.figarosensor/TGS2602.[diakses 03 Februari 2018]

[7.] www.dfrobot.com/wiki/index.php/Capaci tive_Soil_Moisture_Sensor_SKU:SEN01 93. [diakses 03 Februari 2018]
[8.] www.instructables.com/id/USB-to-TTLConverter-PL2303HX/. [diakses 03 Februari 2018] 